\title{
Stefan Perner
}

\section{Grundfreiheiten, Grundrechte-Charta und Privatrecht}

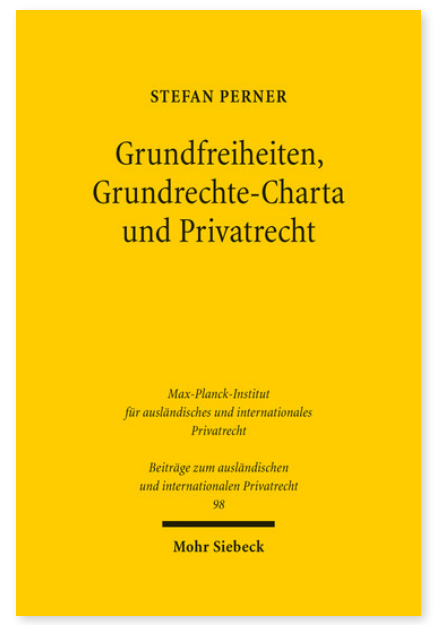

2013. XX, 225 Seiten. BtrIPR 98

ISBN 978-3-16-152638-1

DOI 10.1628/978-3-16-152638-1

eBook PDF 94,00€

ISBN 978-3-16-152637-4

Leinen $94,00 €$
Die EU hat ihren Weg von der Wirtschaftsgemeinschaft der Römischen Verträge zur politisch-sozialen Union fortgesetzt. Vorläufiger Höhepunkt der Entwicklung war das Inkrafttreten der Europäischen Grundrechte-Charta mit dem Vertrag von Lissabon (2009). Stefan Perner nimmt dies zum Anlass, um den Einfluss von wirtschaftsbezogenen Grundfreiheiten und von Europäischen Grundrechten auf das Privatrecht zu untersuchen. Zunächst arbeitet der Autor durch eine am Binnenmarktzweck orientierte Betrachtungsweise eine übergreifende Dogmatik der Grundfreiheiten heraus. Ausgehend davon analysiert er ihren Einfluss auf die nationalen Privatrechte. Anschließend widmet sich die Arbeit den Auswirkungen von Grundfreiheiten und Europäischen Grundrechten im Privatrechtsverhältnis und damit dem aktuellen und umstrittenen Problem der Drittwirkung konstitutioneller Gewährleistungen.

Stefan Perner Geboren 1980; 1999-2002 Studium der Rechtswissenschaften an der Universität Wien; 2004 Promotion; Forschungsaufenthalte am Max Planck-Institut für ausländisches und internationales Privatrecht (Hamburg) sowie an der University of Cambridge (Pembroke College); 2012 Habilitation für die Fächer Bürgerliches Recht, Europarecht und Versicherungsvertragsrecht; Assoziierte Professur für Zivilrecht an der Rechtswissenschaftlichen Fakultät der Universität Wien.

\section{Jetzt bestellen:}

https://mohrsiebeck.com/buch/grundfreiheiten-grundrechte-charta-und-privatrecht-9783161526381?no_cache=1 order@mohrsiebeck.com

Telefon: +49 (0)7071-923-17

Telefax: +49 (0)7071-51104 